\begin{abstract}
Ventless lobster traps are now widely used to assess the abundance of American lobsters (Homarus americanus). However, catch in ventless traps plateaus after $24 \mathrm{~h}$ (trap saturation), possibly influencing abundance estimates. This study addressed 3 mechanisms that may cause ventless trap saturation: 1) traps retain so many lobsters that, over time, fewer lobsters are available to catch; 2) as lobsters accumulate in traps, they inhibit entry of additional lobsters and; 3) bait quality deteriorates over time and loses its attractiveness. We found that 1) the number of lobsters in the vicinity of traps did not change after a 24-h soak; 2) stocking traps with lobsters before deployment lowered subsequent catch, while removing the lobsters captured after $24 \mathrm{~h}$ led to an increase in catch after $48 \mathrm{~h} ; 3$ ) when fresh bait was added to traps that had been fished for $24 \mathrm{~h}$, entry rate immediately increased; 4) if "old" bait was used, catch after $24 \mathrm{~h}$ was less than in traps fished with fresh bait; and 5) amino acid attractants in bait declined after the first 6-24 h. Thus, ventless traps appear to saturate due to a combination of loss of bait attractiveness and the interactions between lobsters as they accumulate in traps.
\end{abstract}

Manuscript submitted 6 September 2018. Manuscript accepted 25 July 2019. Fish. Bull. 117:211-219 (2019).

Online publication date: 15 August 2019. doi: 10.7755/FB.117.3.8

The views and opinions expressed or implied in this article are those of the author (or authors) and do not necessarily reflect the position of the National Marine Fisheries Service, NOAA.

\title{
Experimental analyses of the mechanisms leading to American lobster (Homarus americanus) ventless trap saturation
}

\author{
Winsor H. Watson III (contact author) ${ }^{1}$ \\ Elizabeth Morrissey ${ }^{2}$ \\ Stephanie Sykes ${ }^{1}$ \\ Abigail S. Clark ${ }^{3}$ \\ Steven Jury ${ }^{4}$ \\ Email address for contact author: win@unh.edu \\ 1 Department of Biological Sciences \\ School of Marine Sciences and Ocean Engineering \\ University of New Hampshire \\ 46 College Road \\ Durham, New Hampshire 03824 \\ 2 Marine Institute \\ Memorial University of Newfoundland \\ 155 Ridge Road \\ St. John's, Newfoundland, Canada A1C 5R3 \\ ${ }^{3}$ International Center for Coral Reef Research and Restoration \\ Mote Marine Laboratory \\ 24244 Overseas Highway \\ Summerland Key, Florida 33042 \\ ${ }^{4}$ Department of Biology \\ Saint Joseph's College \\ 278 Whites Bridge Road \\ Standish, Maine 04084
}

The American lobster (Homarus americanus) represents one of the most lucrative fisheries in the United States and Canada, and, therefore, effective management is imperative. This requires accurate monitoring of the abundance of lobsters, of all sizes and sexes, so that declines and distribution shifts, such as the changes that have recently occurred in Southern New England $\left(\mathrm{ASMFC}^{1}\right)$, can be detected and management options can be considered. However, one of the challenges inherent in using the standard traps

\footnotetext{
${ }^{1}$ ASMFC (Atlantic States Marine Fisheries Commission). 2010. Recruitment failure in the Southern New England lobster stock, $30 \mathrm{p}$. [Available from website.]
}

employed by the industry to assess resident lobster populations is that they are designed to capture the larger adults; thus, many of the animals that enter them ultimately escape, especially those that are sublegal (Jury et al., 2001; Barber and Cobb, 2009; Boutson et al., 2009; Weiss, 2010; Sturdivant and Clark, 2011; Broadhurst, et al., 2014).

To address this problem, and improve the quality of the data used for stock assessments, in 2006 the coast-wide ventless trap survey was initiated (see ASMFC, 2015, for details). Ventless traps retain most of the sublegal lobsters that would otherwise escape because the escape vents that are typically present in standard (vented) 
traps are covered or disabled. As a result, the number of lobsters captured per unit of time by these traps can be significantly greater than standard traps, and the size distribution more accurately represents the population on the seafloor (Courchene and Stokesbury, 2011). This leads to a better relationship between catch in ventless traps and the density of lobsters on the bottom than with standard, vented traps (Watson and Jury, 2013). Nevertheless, we recently demonstrated that the catch in ventless traps reaches a plateau, or "saturates," after soak times of $\leq 24 \mathrm{~h}$, even though survey soak times are typically $>3$ days (Clark et al., 2015). This could influence estimates of lobster abundance, especially in areas where the density is high. In their 2015 report, in recognition of this concern, the Atlantic States Marine Fisheries Commission (ASMFC) stated that it was a high priority to conduct further research to help "calibrate" the relationship between ventless trap catch and the density of lobsters on the bottom because "ventless traps may be limited in their ability to differentiate between moderately high and extremely high abundance" (ASMFC, 2015).

Trap saturation, defined by Miller (1979) as a decrease in catch rate with increasing numbers of lobsters in a trap, is a common phenomenon for many types of traps used in a variety of fish and crustacean fisheries (Miller, 1990; Fogarty and Addison, 1997; Stoner, 2004; Hedgärde et al., 2016). In one of the first studies addressing this phenomenon, the "saturation effect" was observed in squirrelfish (Holocentrus adscensionis) and sablefish (Anoplopoma fimbria) pots, and it appeared to be due to a decrease in entry rate as soak time increased (High and Beardsley, 1970). In 1985, Auster demonstrated the asymptotic nature of catch of American lobsters in standard traps over 6-7-day soaks. In 1996, Miller and Rodger reported that standard lobster traps saturated within $12 \mathrm{~h}$ of being deployed. Furthermore, Fogarty and Addison (1997) modeled the effects of multiple variables on standard trap saturation and these models, which included variables associated with entry rate, escape rate, and changes in these variables over time, yielded data that compared favorably with Auster's (1985) data. More recently, using a trap-mounted time-lapse video system, we demonstrated that ventless traps saturate in $\leq 24 \mathrm{~h}$ because they reach a dynamic equilibrium where entry and escape rates are equivalent (Clark et al., 2018). Because the escape rate is low in ventless traps, variability in entry rate is likely a key factor that leads to trap saturation.

Mechanisms that might be responsible for ventless lobster trap saturation, or a plateau in catch after a certain period of time, include 1) deterioration of the bait and/or a decrease in its attractiveness; 2 ) removal/capture of most of the animals in the area fished; and 3) interactions between lobsters in, and around, the trap. The distance of bait attraction for lobsters to standard traps has been previously estimated as approximately $11 \mathrm{~m}$ from the odorant source (Watson et al., 2009), and we expect that ventless traps fish similarly in terms of bait attraction. While the fishable area of a trap will depend upon habitat conditions (e.g., current, temperature, bottom type), lobsters that are already in, or move into, the area of bait attraction will likely to be drawn to the trap. However, as bait is removed by the feeding activity of lobsters and other species, it may deteriorate and this will lead, in part, to a decline in the release of amino acids (and other potential attractants) from the bait over time (Mackie et al., 1980; Løkkeborg, 1990; Kamio and Derby, 2017). Moreover, as bait quality deteriorates, the catch rate of lobsters is also expected to decline because the area of attraction will be reduced, fewer lobsters will be attracted to the trap, and entry rate will decrease.

Although loss of bait attractiveness is a likely factor affecting trap saturation in both standard and ventless traps, it is possible that, at least for ventless traps, capture and retention of many of the lobsters in the effective fishing area (EFA) (Miller, 1975) is another factor. Some of the single-parlor ventless traps fished by the Massachusetts Division of Marine Fisheries have been shown to retain up to 50 lobsters $\left(\mathrm{MADMF}^{2}\right)$. Therefore, depending on the initial density of lobsters on the bottom, after a 24-h soak most of the lobsters within the fishing area of the trap might be retained in the trap, and so there would be few lobsters remaining in the vicinity that could be captured. As a result, approach and entry rates would be reduced, catch rate would plateau, and traps would become "saturated."

Standard and ventless trap saturation is also likely a function of behavioral interactions, with animals in the trap inhibiting the entry of subsequent animals, as Barber and Cobb (2009) demonstrated with Dungeness crabs (Cancer magister). Similar interactions have been observed in and around American lobster traps (Richards et al., 1983; Jury et al., 2001; Watson and Jury, 2013), blue crab (Callinectes sapidus) traps (Sturdivant and Clark, 2011), and cod pots (Anders et al., 2017). It has been proposed that, as traps fill, these antagonistic interactions increase, reducing the further entry of lobsters and increasing the likelihood that lobsters will escape. This phenomenon might be even more pronounced for ventless traps, given their overall greater tendency to rapidly fill with lobsters.

The overall goal of this study was to test 3 possible mechanisms underlying saturation of ventless lobster traps: 1) so many of the lobsters in the fishable area of a trap get captured after $24 \mathrm{~h}$ that entry and exit rates equalize and subsequent catch plateaus; 2 ) catch levels off because the bait loses its attractiveness; and 3) the presence of lobsters in the trap inhibits the entry of additional lobsters.

\section{Materials and methods}

\section{Overview}

We conducted the following 4 types of experiments to test the hypotheses stated above: 1) quantifying the number of lobsters in the vicinity of ventless lobster traps before,

\footnotetext{
${ }^{2}$ MADMF (Massachusetts Division of Marine Fisheries). 2017. Unpubl. data. Mass. Div. Mar. Fish., 251 Causeway St., Ste. 400, Boston, MA 02114.]
} 
and after, a soak time of $24 \mathrm{~h}$ to determine if ventless traps captured enough lobsters to reduce the local population, resulting in fewer entries on the second day of fishing; 2) either pre-stocking ventless traps with lobsters before deploying them, or removing the lobsters captured after the first $24 \mathrm{~h}$, to determine if lobsters in a ventless trap reduce the rate of entry of additional lobsters; 3) fishing ventless traps with new bait, versus 1-day-old "presoaked" bait, to determine if bait loses attractiveness after $24 \mathrm{~h}$; and 4) measuring the rate of leaching of putative lobster attractants from bait to determine if this might explain the reduced entry of lobsters into traps after $24 \mathrm{~h}$ of fishing. Some of these experiments involved deploying traps for $24 \mathrm{~h}$, and in others we soaked traps for $48 \mathrm{~h}$. The methods below, and the results, are organized according to both the type and duration of each experiment.

\section{Study area}

All of the experiments were carried out just off Wallis Sands State Beach in New Hampshire at depths of 7-12 m. This location was chosen based upon previous, comparable studies of lobster trap dynamics that also occurred at this site (Jury et al., 2001; Watson and Jury, 2013; Clark et al., 2015, 2018). Furthermore, the bottom substrate in this location is mostly sand, which makes it easier to conduct replicated, large-scale, transect surveys without having to disturb either the habitat or the lobsters. This habitat type also facilitates analysis of time-lapse videos of lobsters in and around traps. Finally, most commercial lobstermen do not fish in this area, so there was less chance of traps that were not part of our experiment being unexpectedly deployed and influencing the results.

Most of the lobsters captured at this site were below the minimum legal size limit ( $83 \mathrm{~mm}$ in carapace length [CL]), with an average CL of $64.6 \mathrm{~mm}$ (standard deviation [SD] 10.3; range: $34-117 \mathrm{~mm} ; n=3005$; see Clark et al., 2015, for the size-frequency distribution of lobsters captured by ventless traps and observed during scuba surveys at this same study site). In the 12 -week period (mid-July-early October, 2013) during which we conducted this study, the catch per unit of effort remained relatively consistent (Fig. 1).

\section{Traps}

All of the traps used in this study were identical to the single-parlor ventless traps used by the Massachusetts Division of Marine Fisheries and the New Hampshire Fish and Game Department for their ventless trap stock assessment surveys, and they were deployed in the same manner as during their surveys (for details, see Clark et al., 2015). Typically, we used single-parlor traps that were set $\sim 30 \mathrm{~m}$ apart, baited with 3-4 newly thawed Atlantic herring (Clupea harengus) (with a combined weight of approximately $1 \mathrm{~kg}$ ), unless otherwise stated. For a subset of experiments, we used a ventless trap equipped with a lobster trap video (LTV) system (see Jury et al., 2001; Clark et al., 2015, 2018) to observe lobster

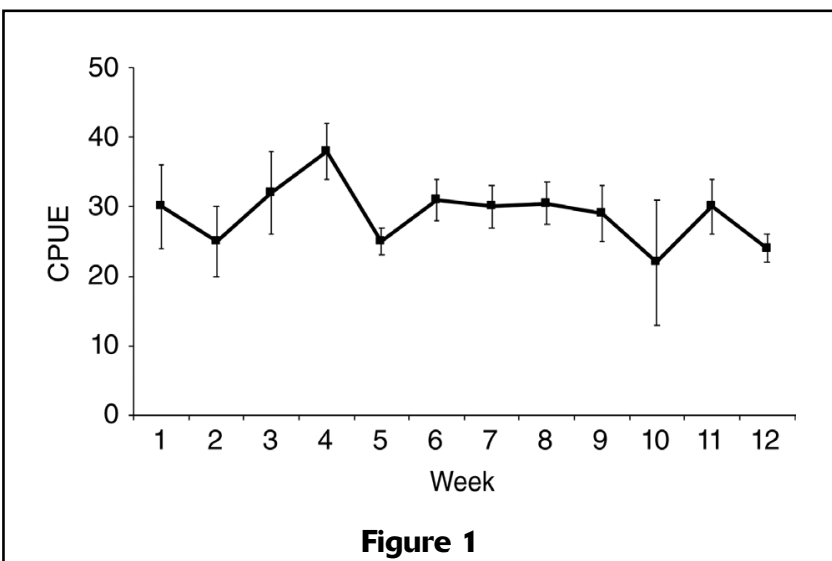

Mean catch per unit of effort of American lobsters (Homarus americanus) in ventless traps deployed off Wallis Sands State Beach in New Hampshire for a 12-week period in 2013 ( 15 July-9 October). All data presented are based on 48-h soak times ( $n=12$, with 8-13 traps deployed per week). Error bars denote standard errors of the mean.

behaviors in and around traps over the course of the soak period. The LTV system in these experiments consisted of a time-lapse digital video camera and recorder (Brinno BCC200 ${ }^{3}$, Brinno, Inc., Taipei City, Taiwan) secured inside an Ikelite clear plexiglass case (Ikelite, Indianapolis, IN) that was mounted above the trap on a PVC frame. Video frames were captured every $5 \mathrm{~s}$, and video recordings were played back at 15 frames/s during analysis. The videos were taken only during the daylight hours of a typical 48-h soak because no supplemental light source was used in order to avoid the potential influence of artificial lights on lobster behavior.

\section{Density of lobsters around traps before and after a 24-h soak}

This experiment was designed to determine if ventless traps temporarily reduce the number of American lobsters in the vicinity of a trap after deployment for $24 \mathrm{~h}$. On day 1 of the experiment, a single trap without bait was deployed, and then a pair of scuba divers conducted a transect survey of lobster abundance around the trap as described below. During each survey, divers swam 4 transects of $30 \mathrm{~m}$ each, extending out from the trap in the 4 cardinal directions. This distance was chosen because the fishable area of a trap is an estimated $2600 \mathrm{~m}^{2}$, or a circle with a radius of $28.8 \mathrm{~m}$, based upon data from a study by Watson et al. (2009). The width of each transect was typically 2-4 m, depending on visibility, yielding a survey area of $240-480 \mathrm{~m}^{2}$ for each experiment. Immediately after completing the survey, the divers opened a watertight container of bait and placed it in a previously empty bait bag, in the trap. Lobsters were not handled during

\footnotetext{
${ }^{3}$ The mention of trade names or commercial companies is for identification purposes only and does not imply endorsement by the National Marine Fisheries Service, NOAA.
} 
the surveys conducted on day 1 because handling often leads to an escape response or other aberrant behavior, which might have caused them to leave the area (senior author, personal observ.). After the trap had been deployed for $24 \mathrm{~h}$, the dive survey described above was repeated to determine if the density of lobsters around the trap had changed. This experiment was repeated on 5 different occasions. A Wilcoxon matched-pairs signed rank test $(n=5)$ was used to compare the density of lobsters present before and after the trap had soaked for $24 \mathrm{~h}$.

\section{Influence of lobsters in a trap on the entry of additional lobsters}

American lobsters in a ventless trap may deter the entry of additional lobsters and thus reduce the rate of entry, leading to a plateau in catch (trap saturation). We conducted experiments with soak times of $24 \mathrm{~h}$ and $48 \mathrm{~h}$ to test this hypothesis and we both added lobsters to a trap (prestocked) and removed lobsters that were captured after $24 \mathrm{~h}$ from a trap, before redeploying it for another $24 \mathrm{~h}$.

Pre-stocking experiment with 24-h soak Between 1 August 2013 and 2 October 2013, 6 different ventless traps were pre-stocked with all of the lobsters that were caught from 6 other ventless traps that had been deployed for $24 \mathrm{~h}$. The number of lobsters used for pre-stocking was a function of the number of lobsters initially captured; lobsters were transferred directly from one ventless trap to another. The average number of lobsters used to pre-stock traps was 28.6 (SD 4.2; range: 21-33). Importantly, these lobsters had a size-frequency distribution that was typical for lobsters captured by ventless traps in this location. The lobsters used for pre-stocking were also marked, with a coded rubber band placed on the carpus of each of their claws (i.e., "knuckles"), so that they could be differentiated from any subsequently captured lobsters. We confirmed that the tags remained on lobsters for at least 1 week in a separate study conducted at the University of New Hampshire (UNH) Coastal Marine Laboratory (New Castle, New Hampshire). Pre-stocked ventless traps were provided with fresh bait and deployed in locations at least $0.5 \mathrm{~km}$ away from where the traps used to capture the lobsters for pre-stocking were fished, but in the same general fishing area. The pre-stocked ventless traps were then deployed for $24 \mathrm{~h}$ and catch was compared to the catch in the ventless traps that were initially used to capture the lobsters used for pre-stocking. The Mann-Whitney U test was used for this comparison, as well as for subsequent analyses when catch was compared between 2 groups of traps.

Trap emptying experiment with 48-h soak In this study, which was conducted between 1 August 2013 and 9 October 2013, ventless traps $(n=9)$ were deployed for $24 \mathrm{~h}$ and then hauled. All captured lobsters were removed, but the used bait in each trap was retained. The lobsters were then released $>0.5 \mathrm{~km}$ from where they were captured to minimize the chance of subsequent recapture. These traps, emptied of lobsters, were redeployed with the same 1-day-old bait for an additional 24-h soak. The catch from the initial 24-h deployment with fresh bait was compared with catch during the second 24-h soak of the same trap with the 1-day-old bait. The net catch for the entire soak time of $48 \mathrm{~h}$, or the sum of the animals captured on day 1 , plus those captured on the day 2, was also compared with catch from control ventless traps $(n=27)$ that were deployed continuously for $48 \mathrm{~h}$ during the same time period, within the same study area.

\section{Loss of bait attractiveness}

Studies testing the hypothesis that bait loses at least some of its attractiveness over a soak were also conducted with traps deployed for both $24 \mathrm{~h}$ and $48 \mathrm{~h}$.

Bait experiment 1: 24-h-old versus fresh bait Traps $(n=33)$ were deployed for $24 \mathrm{~h}$ and then the used bait was removed and placed into different ventless traps. These traps were then then redeployed with the 1-day-old bait in a different location, $>0.5 \mathrm{~km}$ away, but in the same general study area. Catch in the original traps, fished with fresh bait for $24 \mathrm{~h}$, was compared with catch in the traps fished with 1-day-old bait for $24 \mathrm{~h}$.

Bait experiment 2: 48-h soak with rebait Ventless traps ( $n=27$ ) were deployed for $24 \mathrm{~h}$ and hauled, the used bait was removed, and then the traps were rebaited with the same amount of fresh bait. Lobsters in each trap were counted but not removed from the trap, and the traps were redeployed and fished for another $24 \mathrm{~h}$. In a supplementary experiment using a ventless trap equipped with a LTV system $(n=7)$, the fresh bait was added by scuba divers after a soak of $24 \mathrm{~h}$ so that video recordings would not be interrupted by hauling of the trap and any lobsters retained by the trap up to this point would not be startled, potentially influencing their behavior. After an additional 24-h soak with the new bait (48-h total soak time), the trap was hauled and the captured lobsters quantified. The catch for the traps that received fresh bait $(n=27)$ was compared to the catch in control ventless traps $(n=34)$ that were continuously deployed with the same bait for $48 \mathrm{~h}$, in the same general area and during the same time period.

We also used data from the 7 trials with the LTV system, described above, to quantify the number of lobsters that entered and escaped from traps during experiments in which scuba divers added fresh bait. In addition, the videos obtained allowed us to determine the total number of lobsters in the trap each hour (i.e., accumulated catch), so that the time course of saturation could be plotted.

Bait experiment 3: leaching of amino acids This experiment was conducted to determine the relative rate at which amino acids leached out of bait over $24 \mathrm{~h}$. Salted Atlantic herring (4 samples, each with a wet weight of $150 \mathrm{~g}$ ) were put in individual bait bags, which were then placed into 1-L beakers containing clean artificial seawater with a practical salinity of 32 (Crystal Sea Marinemix, Marine Enterprises International, LLC, Baltimore, MD) and gently 
mixed for $1 \mathrm{~h}$ on a shaker table in a temperature-controlled bath $\left(20^{\circ} \mathrm{C}\right)$. The soaked bait and particulates were then allowed to settle for $15 \mathrm{~min}$, and duplicate $15-\mathrm{mL}$ aliquots of the supernatant were removed and frozen at $-20^{\circ} \mathrm{C}$ for future analyses. The bait remaining after this 1 - $h$ period was weighed and then placed inside a bait bag and transferred to a ventless lobster trap that had the entries covered to minimize possible feeding on the bait by lobsters or other organisms too large to fit through the trap mesh. These traps were deployed in the field in Casco Bay, Maine $\left(15^{\circ} \mathrm{C}\right.$, salinity of 32$)$, for periods of 3,6 , and $24 \mathrm{~h}$, and then the bait from each trap was weighed. After each time interval of soaking in the field, each bait bag with remaining bait was placed into $1 \mathrm{~L}$ of temperature-controlled, clean artificial seawater and shaken in the lab for another hour, after which duplicate leachate aliquots were removed and frozen. Thus, for each of the 4 bait samples tested, we had the wet weight of the bait and a leachate sample for 4 time periods: $0-1 \mathrm{~h}, 3-4 \mathrm{~h}, 6-7 \mathrm{~h}$, and $24-25 \mathrm{~h}$. For amino acid analyses, leachate samples were sent to SGS Analytical Services (Brookings, SD) for standard analyses via liquid chromatography-mass spectrometry.

\section{Results}

\section{Density of lobsters around traps before and after a 24-h soak}

There was no significant difference between the density of lobsters in the vicinity of ventless traps before and after a soak of 24 h (Fig. 2; 2-tailed Wilcoxon test: $n=5, P=0.125$ ). Even when the density of lobsters determined by scuba surveys was at its highest, there were more lobsters around the trap after $24 \mathrm{~h}$ than just after the trap was set. Therefore, with the possible exception of times of the year when, or locations where, densities of lobsters are very low,

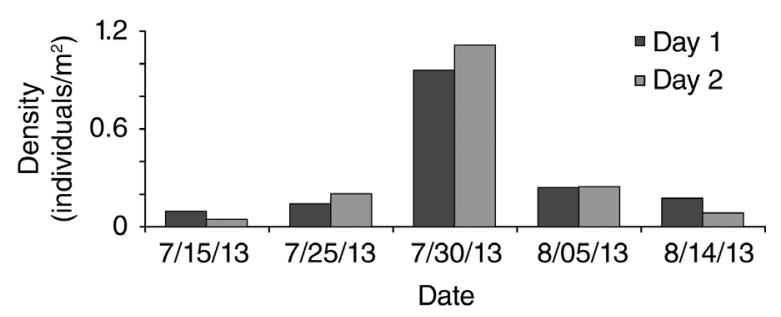

Figure 2

The abundance of American lobsters (Homarus americanus) in the vicinity of a trap prior to, and after, a soak of $24 \mathrm{~h}$. Traps were deployed in 2013 off Wallis Sands State Beach in New Hampshire. There was no significant difference ( $n=5, P=0.125$ ) in the density of lobsters before, and after, a trap had been deployed for $24 \mathrm{~h}$. Therefore, traps did not reduce the number of lobsters in the area surrounding the traps significantly enough to influence catch on day 2 of a 48 -h soak. Gray bars represent day 1, and black bars represent day 2 . it appears that the reduction in the number of lobsters in the EFA of a trap, due to their accumulation in a ventless trap, is probably not a primary cause of trap saturation.

Influence of lobsters in a trap on the entry of additional lobsters

Catch in pre-stocked traps versus control traps deployed for $\mathbf{2 4} \mathrm{h}$ Pre-stocked traps captured significantly fewer additional lobsters than traps that were not pre-stocked (Fig. 3; Mann-Whitney $\mathrm{U}$ test: $P=0.002)$. An average of 12.2 new lobsters entered the pre-stocked traps in $24 \mathrm{~h}$, while 7.8 of the marked lobsters used for pre-stocking escaped, yielding a net increase in catch of only 4.4 lobsters (SD 3.7). This indicates that lobsters in ventless traps influence the subsequent entry of additional lobsters, as has been observed for standard traps (Jury et al., 2001). When taken together with the fact that a number of the pre-stocked lobsters escaped, it appears as if, at some point during a soak, as traps fill, a dynamic equilibrium between entries and escapes is reached, which plays an important role in causing catch to plateau, or saturate, in ventless traps.

Removal of captured lobsters after $24 \mathrm{~h}$ of a soak influences catch after $48 \mathrm{~h}$ Traps ( $n=9)$ deployed for $24 \mathrm{~h}$ captured an average of 25.7 lobsters (SD 6.1). After these lobsters were removed from the traps and the same traps were redeployed without changing the bait for a second $24 \mathrm{~h}$, they captured significantly fewer lobsters in the second 24-h soak period (13.7 individuals [SD 8.6]; Mann-Whitney $\mathrm{U}$ test: $P=0.004)$. Moreover, if the number of lobsters captured during each of the 2 days are added together, a net total of 39.3 lobsters (SD 12.9) were caught in the equivalent of a 48-h soak. This was significantly more than the

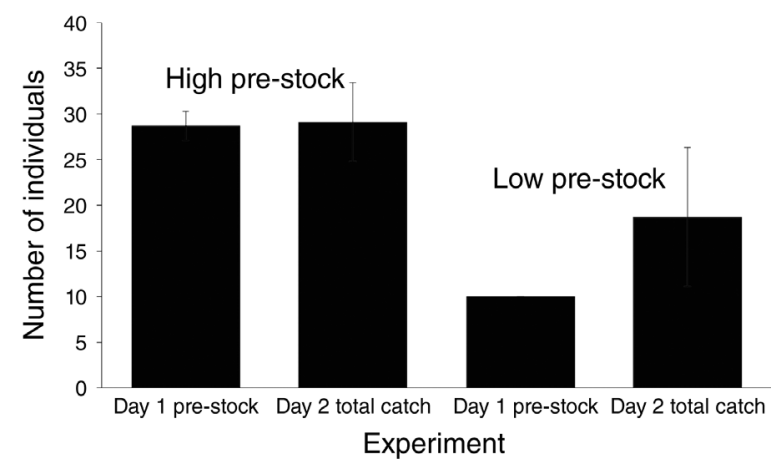

Figure 3

The effect of pre-stocking traps on subsequent catch. When traps $(n=6)$ were pre-stocked with $\sim 28$ American lobsters (Homarus americanus) on day 1 (high pre-stock), the traps captured few additional lobsters after a soak of $24 \mathrm{~h}$ (day 2 ). When traps ( $n=3$ ) were pre-stocked with only 10 lobsters (low pre-stock), they caught $\sim 9$ more lobsters during the next $24 \mathrm{~h}$, for a total of $\sim 19$. Error bars in this figure denote standard errors of the mean. 
catch in nearby ventless traps that were deployed for $48 \mathrm{~h}$ without the removal of lobsters (28.9 individuals [SD 9.4]; Mann-Whitney U test: $P=0.035$ ). These data indicate that 1 ) bait is less attractive after $24 \mathrm{~h}$ and 2) lobsters already in a trap influence the entry of new lobsters, so if they are removed, more lobsters will enter the trap.

\section{Loss of bait attractiveness}

Traps deployed for $\mathbf{2 4} \mathrm{h}$ with fresh or old bait Ventless traps $(n=33)$ that were fished for $24 \mathrm{~h}$ with "fresh" bait captured significantly more lobsters (unpaired $t$-test: $P<0.006)$ than ventless traps $(n=29)$ fished with bait that had been previously used for $24 \mathrm{~h}$ in a different set of traps (i.e., 1-day-old bait) (Fig. 4A). These results indicate that the old bait was less attractive than the new bait. It should be noted that, although this old bait had been in a trap for $24 \mathrm{~h}$, much of the Atlantic herring, by weight, was still intact (on average, $62 \%$ of the bait by wet weight remained).

Traps deployed for $48 \mathrm{~h}$ Ventless traps $(n=34)$ were deployed for $24 \mathrm{~h}$ and then the bait was replaced with new bait, and the traps were redeployed, without removing any of the captured lobsters, for a second $24 \mathrm{~h}$. These traps with bait added captured a mean of 21.0 lobsters after the initial $24 \mathrm{~h}$ and 13.9 lobsters during the second $24 \mathrm{~h}$, for a total of 34.9 lobsters after the total soak time of $48 \mathrm{~h}$ (Fig. 4B). This was significantly more than control traps ( $n=27)$ captured; control traps were fished over the same time period, but without new bait added after the initial $24 \mathrm{~h}$ (unpaired $t$-test: $P<0.05$ ) (Fig. 4B). Interestingly, the experimental traps with added bait captured $\sim 50 \%$ fewer lobsters on day 2 than on day 1 in virtually every experiment, even though fresh bait was added, a result that was likely due to the influence of the lobsters retained from day 1 on the subsequent entry of new lobsters. Therefore, while loss of bait attractiveness appears to play a role in reducing the catch of lobsters during day 2 of a 48-h soak, other factors, such as the behavioral interactions between lobsters, also influence saturation of ventless traps.

Attractants leaching from bait To estimate the leaching of possible bait attractants from Atlantic herring within the first $24 \mathrm{~h}$ of trap deployment, we measured changes in the concentrations of various amino acids over time in simulated trap deployments (Fig. 5). Although the weight of the Atlantic herring that were used as bait was essentially

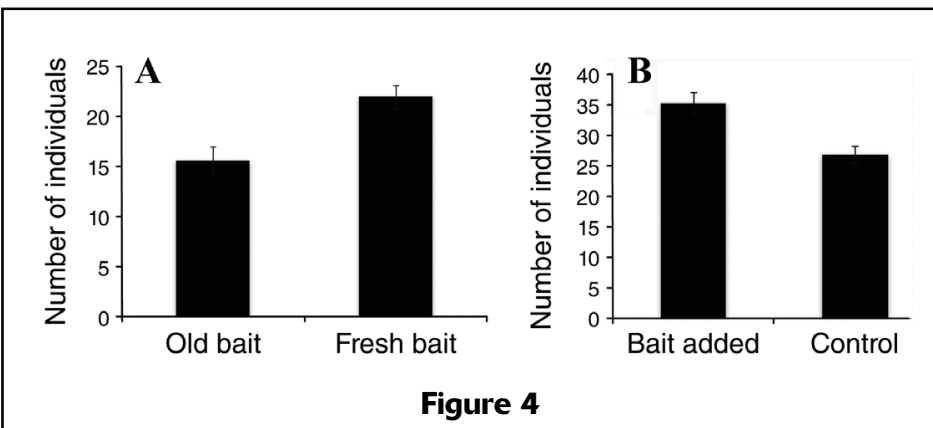

The effect of bait "age" on catch per unit of effort. (A) Twenty-nine traps were deployed for $24 \mathrm{~h}$ with bait that had already been used in different traps in the same location for $24 \mathrm{~h}$ (old bait), and 33 other traps were deployed for $24 \mathrm{~h}$ with the same amount of fresh bait. The traps with fresh bait captured significantly more American lobsters (Homarus americanus) $(P<0.006)$. (B) Control traps $(n=34)$ were deployed for $48 \mathrm{~h}$ with the same bait. Experimental traps ( $n=34$, bait added) were hauled after $24 \mathrm{~h}$, the bait in each trap was replaced with fresh bait, and then the traps were redeployed for an additional $24 \mathrm{~h}$. The traps with added bait caught significantly more lobsters $(P=0.027)$. Error bars in this figure denote standard errors of the mean.

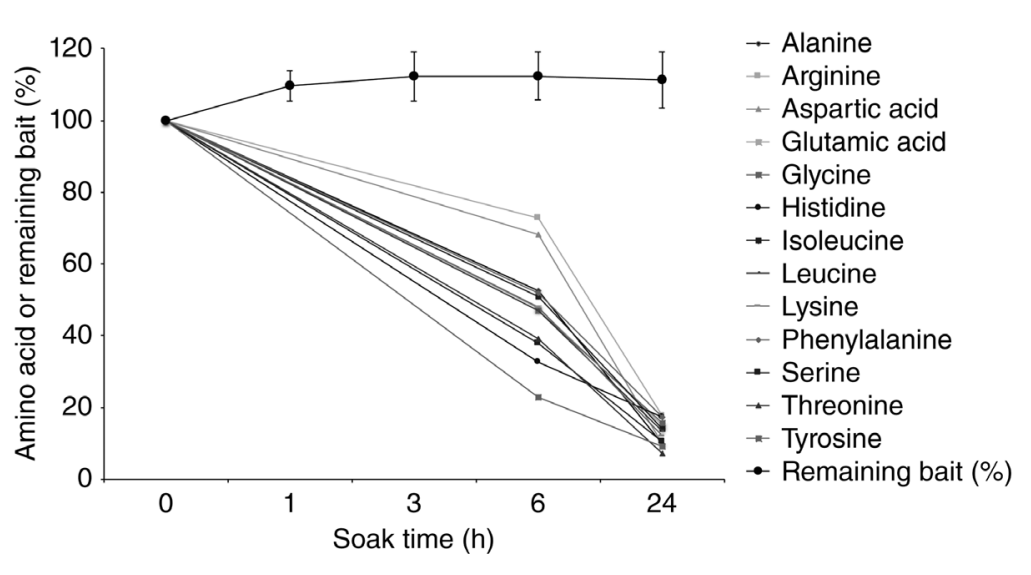

Figure 5

Bait degradation over time, by proportion of remaining weight (\%) and relative concentration (\%) of amino acids. Although wet weight of the bait $(n=4$, frozen salted Atlantic herring, Clupea harengus), was relatively unchanged over a 24-h simulated trap deployment, the concentrations of multiple amino acids rapidly decreased due to leaching. Note that the initial increase in weight is due to rehydration of the salted herring. Error bars in this figure denote standard errors of the mean. unchanged after $24 \mathrm{~h}$ (note that lobsters were not allowed to feed on baits during the soak time; for details, see the "Materials and methods" section), the amino acid concentrations decreased by 30-80\% after just $6 \mathrm{~h}$ and then decreased even further after $24 \mathrm{~h}$. As a result, under the conditions tested, salted Atlantic herring after $24 \mathrm{~h}$ had 
$<20 \%$ of its initial concentration of potential attractants. In the field, the decrease in attractiveness would likely be even greater because feeding on the bait would reduce its quantity and increase the rate of leaching. These data add further support to the hypothesis that even though loss of bait attractiveness is not the only factor influencing ventless trap saturation, it is a key factor leading to a decrease in the rate of lobster entries into a trap even after a soak of just $24 \mathrm{~h}$.

Time-lapse video observations of ventless traps For insight into the behavioral mechanisms underlying the effect of new versus old bait, time-lapse videos of ventless traps $(n=7)$ were obtained before and after the addition of fresh bait (Fig. 6). Data from analysis of these videos indicate that the entry of lobsters typically leveled off on day 2 of a soak, but when fresh bait was added by divers on day 2 there was an immediate increase in the entry of lobsters into the trap (Fig. 6). As a result, while the entry rate of lobsters in control traps dropped $77 \%$ between day 1 and 2 (from 1.7 to 0.4 entries/h), it only dropped $38 \%$, from 1.6 to 1.0 entries $/ \mathrm{h}$, for experimental traps with fresh bait added.

\section{Discussion}

Although the mechanisms underlying trap saturation in standard lobster traps have been addressed in a number of previous studies (Miller, 1979; Richards et al., 1983; Fogarty and Addison, 1997; Jury et al., 2001), the focus of this study was the testing of specific hypotheses concerning the potential causes of ventless trap saturation. Our results indicate that catch typically reaches a plateau after $\sim 24 \mathrm{~h}$ for 2 main reasons: 1) a loss of bait attractiveness, which leads to a decrease in the rate of entries; and 2) behavioral interactions between American lobsters, which become more prevalent as traps fill and cause both a decrease in the entry of new lobsters and an increase in the rate of escapes. These conclusions are supported by data showing that, if fresh bait was added, or lobsters in a trap were removed, catch was higher than in control traps, and if old bait was used, or lobsters were pre-stocked in traps, catch declined relative to catch in control traps (Fig. 7). These same mechanisms are likely to come into play with standard traps as well, but the relative rates of entry and escape differ, leading to different behavioral dynamics.

In a previous study, Clark et al. (2015) demonstrated that ventless traps saturate before they reach capacity (i.e., they reach the maximum biomass they can hold) and

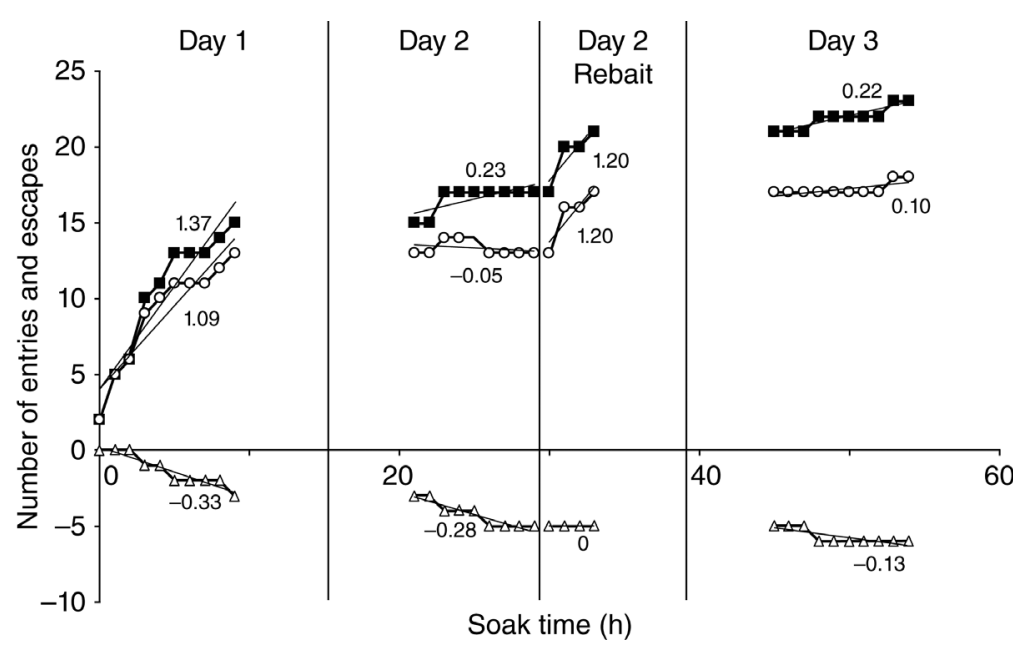

Figure 6

The effect of fresh bait on the entry rate of American lobsters (Homarus americanus) into traps deployed off New Hampshire in 2013, based on video observations. The accumulated rates of entry (black squares), catch (white circles), and escapes (white triangles) are shown for one representative 72-h soak of a ventless trap. Lines that best fit the data are overlaid on each segment of data points. Note that on day 2 (after traps already had been fished for $24 \mathrm{~h}$ ), rates of entry and catch reached a plateau. Then scuba divers added fresh bait to the trap (vertical line labelled Day 2 rebait), which led to an immediate increase in entries and catch. Also note that, when escapes were equivalent to entries, catch reached a plateau. Missing data are the result of night hours when observations were not possible because lights were not used on traps.
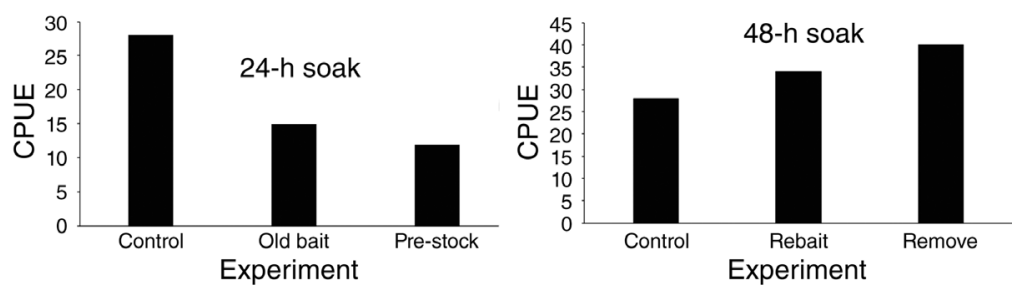

Figure 7

Summary overview of the effects of various experiments on the catch per unit of effort (CPUE) of American lobsters (Homarus americanus) in ventless traps. These data are presented in summary for comparison; therefore, error bars have been omitted. Note that pre-stocking traps and using 1-day-old bait reduces catch, compared with catch of control traps (24-h soak), and that removing the lobsters captured on day 1, or adding fresh bait after $24 \mathrm{~h}$, led to an increase in catch. The CPUE data for the "remove experiment" includes the lobsters that were removed on day 1 and the new lobsters captured on day 2. 
that catch at the point of saturation is correlated with the density of American lobsters on the bottom. Saturation tended to occur when the rate of entry of lobsters into ventless traps became equal to their rate of escape, so lobsters stopped accumulating in the trap, and the catch rate reached a plateau (Clark et al., 2018). Importantly, these data indicate that ventless traps probably saturate before they reach some upper physical capacity, or maximum number of lobsters the trap could hold. Therefore, ventless traps seem to provide a fairly accurate index of the number of lobsters on the bottom, at least when the density of lobsters on the bottom is not very high (Watson and Jury, 2013; Clark et al., 2015).

Previously, Clark et al. (2018) determined, using video cameras mounted above traps, that the number of lobsters within $1 \mathrm{~m}$ of both standard and ventless traps was less on day 2 of a 48 -h soak than on day 1 . Given that ventless traps typically capture $\geq 30$ lobsters in the area studied by Clark et al. (2018) (i.e., same site used in the present study) during a 48 -h soak (Fig. 1), the ventless traps may have accumulated enough lobsters to reduce the density of lobsters in the EFA surrounding the traps. In this study, we surveyed a much larger area around traps and found that there were no significant differences in the densities of lobsters in the EFA after the traps were deployed for $24 \mathrm{~h}$. These findings do not support the hypothesis that ventless traps saturate because they accumulate enough lobsters to reduce the density in their vicinity.

One reason why some American lobsters do not enter traps is that conspecifics already inside the traps keep them out (Richards et al., 1983). During 2 previous studies (Jury et al., 2001; Watson and Jury, 2013), time-lapse videos were used to investigate this phenomenon with standard lobster traps, and, in both cases, it was clear that lobsters in the kitchen portion of the trap, where lobsters enter and the bait is located, would often prevent other lobsters from entering. However, it should be noted that in all previous studies of this type the lobsters used for pre-stocking were large adults that might be more aggressive than the sublegal lobsters that typically accumulate in ventless traps.

In this study, ventless traps were pre-stocked with the same number, and size composition, of lobsters that were typically captured in ventless traps on day 1 of a soak, in the same location (see Clark et al., 2015), and despite this modification in protocol, pre-stocking traps still reduced catch. Also, the removal of the lobsters captured on day 1 increased the number of lobsters captured on day 2, most likely because of reduced agonistic interactions. Moreover, when the lobsters captured and removed on day 1 of a 48-h soak were added to those captured on day 2 , the total net catch was greater than that for traps that were deployed continuously for $48 \mathrm{~h}$ (Fig. 7). This result indicates that as a trap fills over the course of the soak time, fewer lobsters enter, and more lobsters leave, leading eventually to a dynamic equilibrium in which catch plateaus. However, although it appears as if the reduction in the rate of entry is, in part, due to the presence of lobsters in the trap, loss of bait attractiveness also appears to play an important role.
Bait attractiveness was reduced after $24 \mathrm{~h}$, as indicated by a number of different results. First, catch of traps with 1-day-old bait was significantly less than catch of identical traps deployed for $24 \mathrm{~h}$ with fresh bait (Fig. 4). Second, when scuba divers replaced old bait with fresh bait, there was an immediate increase in the rate of entries observed on video recordings made with the LTV system. This finding strongly indicates that the new bait was significantly more attractive than the old bait (Fig. 6). Moreover, traps that had new bait added after $24 \mathrm{~h}$ captured more lobsters than control traps (Fig. 4). Finally, after 6-24 h, there was a significant reduction in the amount of amino acids released from Atlantic herring bait, even though the bait itself, in terms of weight, was mostly intact. These results are consistent with those of a previous study of the rate of leaching from mackerel bait (Løkkeborg, 1990). Therefore, a change in the attractiveness of bait over time also plays a key role in lobster trap dynamics and the onset of ventless trap saturation. It should be noted that the initial amount and type of bait, along with environmental factors such as temperature and current velocity, will likely affect catch and trap saturation by altering the rate at which bait loses its attractiveness.

The findings from this study have several practical implications. First, ventless traps saturate after approximately $24 \mathrm{~h}$ because of a combination of factors related to bait deterioration and behavioral interactions between lobsters that inhibit further entries and enhance escapes. Therefore, in areas with high densities of lobsters, soak times of $\sim 24 \mathrm{~h}$ might be best for ventless trap surveys. However, longer soak times might be appropriate in areas where the density of lobsters is lower or where the size-frequency distribution is different. Second, even though there is a correlation between catch in ventless traps and the density of lobsters on the bottom (Clark et al., 2015), the accuracy of catch in ventless trap surveys as an indicator of abundance might be affected in areas with higher densities of lobsters or, as mentioned previously, in habitats with a higher density of larger, more aggressive lobsters. In these areas, one possible solution might be to use double-parlor ventless traps, which might saturate at a higher capacity, or after a longer soak time. Finally, it would be prudent to consider standardization of the amount and type of bait used in ventless traps and to consider bait or bait delivery systems that do not deteriorate as fast as Atlantic herring, so that lobsters will continue to approach and enter traps at a high rate throughout a longer soak time.

\section{Acknowledgments}

We thank the staff at the UNH Coastal Marine Laboratory, including W. Howell, N. Rennels. and the late N. Carlson, as well as UNH students, J. Goldstein, N. Copp, H. Cheng, B. Dubofsky, and T. Langley and Southern Maine Community College students under the supervision of $B$. Tarbox. We also thank the Massachusetts Division of Marine Fisheries, J. Carloni, and T. Pugh. This work was supported by a faculty development grant from 
St. Joseph's College to S. Jury and funding from New Hampshire Sea Grant (NOAA award R/SSS-3) to W. Watson.

\section{Literature cited}

ASMFC (Atlantic States Marine Fisheries Commission).

2015. American lobster benchmark stock assessment and peer review report, 417 p. Atlantic States Mar. Fish. Comm., Arlington, VA. [Available from website.]

Anders, N., A. Fernö, O.-B. Humborstad, S. Løkkeborg, G. Rieucau, and A. C. Utne-Palm.

2017. Size-dependent social attraction and repulsion explains the decision of Atlantic cod Gadus morhua to enter baited pots. J. Fish Biol. 91:1569-1581. Crossref

Auster, P.

1985. Factors affecting catch of American lobster, Homarus americanus, in baited traps. Univ. Conn. Sea Grant Program, Tech. Bull. Ser. CT-SG-85-1, 46 p.

Barber, J. S., and J. S. Cobb.

2009. Qualitative observations of Dungeness crabs, Cancer magister, in and around traps: evidence of resource guarding and clustering. Mar. Freshw. Behav. Physiol. 42:135146. Crossref

Boutson, A., C. Mahasawasde, S. Mahasawasde, S. Tunkijjanukij, and T. Arimoto.

2009. Use of escape vents to improve size and species selectivity of collapsible pot for blue swimming crab Portunus pelagicus in Thailand. Fish. Sci. 75:25-33. Crossref

Broadhurst, M. K., P. A. Butcher, and B. R. Cullis.

2014. Effects of mesh size and escape gaps on discarding in an Australian giant mud crab (Scylla serrata) trap fishery. PLoS ONE 9(9):e106414. Crossref

Clark, A. S., S. H. Jury, J. S. Goldstein, T. G. Langley, and W. H. Watson III.

2015. A comparison of American lobster size structure and abundance using standard and ventless traps. Fish. Res. 167:243-251. Crossref

2018. Underwater video surveillance of American lobsters (Homarus americanus) to understand saturation levels in lobster traps. Fish. Bull. 116:161-170. Crossref

Courchene, B., and K. D. E. Stokesbury.

2011. Comparison of vented and ventless trap catches of American lobster with scuba transect surveys. J. Shellfish Res. 30:389-401. Crossref

Fogarty, M. J., and J. T. Addison.

1997. Modelling capture processes in individual traps: entry, escapement and soak time. ICES J. Mar. Sci. 54:193-205. Crossref

Hedgärde, M., C. W. Berg, L. Kindt-Larsen, S. G. Lunneryd, and

S. Königson.

2016. Explaining the catch efficiency of different cod pots using underwater video to observe cod entry and exit behaviour. J. Ocean Technol. 11(4):67-90.
High, W. L., and A. J. Beardsley.

1970. Fish behavior studies from an undersea habitat. Commer. Fish. Rev. 32:31-37.

Jury, S. H., H. Howell, D. F. O'Grady, and W. H. Watson III.

2001. Lobster trap video: in situ video surveillance of the behavior of Homarus americanus in and around traps. Mar. Freshw. Res. 52:1125-1132. Crossref

Kamio, M., and C. D. Derby.

2017. Finding food: how marine invertebrates use chemical cues to track and select food. Nat. Prod. Rep. 34:514-528. Crossref

Løkkeborg, S.

1990. Rate of release of potential feeding attractants from natural and artificial bait. Fish. Res. 8:253-261. Crossref

Mackie, A. M., P. T. Grant, R. G. J. Shelton, B. T. Hepper, and P. R. Walne.

1980. The relative efficiencies of natural and artificial baits for the lobster, Homarus gammarus: laboratory and field trials. ICES J. Mar. Sci. 39:123-129. Crossref

Miller, R. J.

1975. Density of the commercial spider crab (Chionoecetes opilio), and calibration of effective area fished per trap using bottom photography. J. Fish. Res. Board Can. 32:761768. Crossref

1979. Saturation of crab traps: reduced entry and escapement. ICES J. Mar. Sci. 38:338-345. Crossref

1990. Effectiveness of crab and lobster traps. Can. J. Fish. Aquat. Sci. 47:1228-1251. Crossref

Miller, R. J., and R. S. Roger.

1996. Soak times and fishing strategy for American lobster. Fish. Res. 26:199-205. Crossref

Richards, R. A., J. S. Cobb, and M. J. Fogarty.

1983. Effects of behavioral interactions on the catchability of American lobster, Homarus americanus, and two species of Cancer crab. Fish. Bull. 81:51-60.

Stoner, A. W.

2004. Effects of environmental variables on fish feeding ecology: implications for the performance of baited fishing gear and stock assessment. J. Fish Biol. 65:14451471. Crossref

Sturdivant S. K., and K. L. Clark.

2011. An evaluation of the effects of blue crab (Callinectes sapidus) behavior on the efficacy of crab pots as a tool for estimating population abundance. Fish. Bull. 109:48-55.

Watson, W., and S. H. Jury.

2013. The relationship between American lobster catch, entry rate into traps and density. Mar. Biol. Res. 9:59-68. Crossref

Watson, W. H. III, W. Golet, D. Scopel, and S. Jury.

2009. Use of ultrasonic telemetry to determine the area of bait influence and trapping area of American lobster, Homarus americanus, traps. N.Z. J. Mar. Freshw. Res. 43:411-418. Crossref

Weis, J. S.

2010. The role of behavior in the success of invasive crustaceans. Mar. Freshw. Behav. Physiol. 43:83-98. Crossref 